\title{
The Leo Model
}

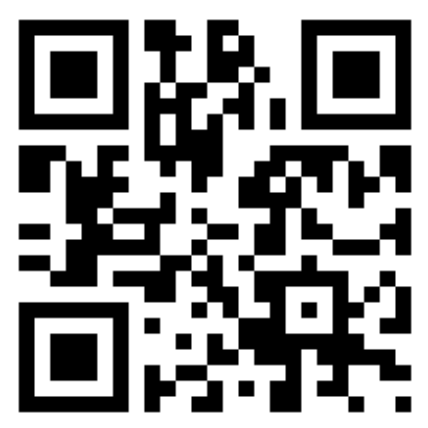

E alofa le Atua ia te a'u Ma mea matagofie o'u vaa'i i ai Le nuanua o lo'o susulu i lo'u faamalama

E alofa le Atua ia te a'u.
My God loves me And all the wonders I see The rainbow shines through my window My God loves me

The word Leo is the Samoan word for voice. My model (scan the QR code) uses the sound of my vocals to illustrate its values and principles in relation to one another. I am using an old Sabbath school song my grandmother taught me which is also the first Samoan song I learnt as a child called "My God Loves Me"

It is through songs I learnt the Samoan language, through songs I learnt of God's love for me. Singing is one of my family's strongest means of communication with each other. It felt natural to convey the Leo model through using the sound of 
voice. "In indigenous societies, oral traditions form the "distinct ways of knowing and the means by which knowledge is reproduced, preserved and conveyed from generation to generation" (McNab.D, 2013)

I believe the voice is the most important instrument we have and own. After much thought and numerous attempts with drawing picture's and symbols to show my model through, I had come to realize, the Leo model is not meant to be drawn, it is meant to be sung. To see this another way, using vocals I can demonstrate my model in a more creative way which may be more appealing to the imaginative, creative, artistic and musically inclined.

The Leo model has five dimensions:

- God O LE ATUA (could be the beliefs of a person)

- You O A'U (includes everything around wellbeing, spiritual, physical, mental and emotional of a person)

- Family AIGA (community, wider community)

- Love ALOFA (love for yourself, love for what you do, love for others)

- Respect FA'AALOALO (respect for other thoughts, feelings, space and environment)

Growing up a Samoan, Māori woman I have had the best of both worlds. My parents knew the importance in making sure me and my little sister spent time with both sides of the family, learning about the different cultures. Both families have similar values and principles within the home in which they teach and live by. It is through these teachings and my lived experiences I have developed my model through.

My grandmother taught me to keep God at the centre of my life and everything will fall into place. She would say, even though this world and the people in it may change, He will remain the same. "Jesus Christ is the same yesterday, today and forever." (Hebrews 13:8 NIV) 


\section{The Leo features explained:}

God O LE ATUA (beliefs of a person)

To begin my sound model, you will hear just one voice. This voice stays the same throughout the piece it does not change. It is the underlying melody in which the other voices get their note from to harmonize and gives direction in knowing where to go.

For me this voice represents God but for others, it may be their beliefs, values or principles that center their lives. Every other feature surrounding this source has been given life and meaning because the center gives you purpose.

You O A'U (includes everything around wellbeing, spiritual, physical, mental and emotional of a person) and

Family AIGA (community, wider community). The next sound you will hear another voice to support and accompany.

The extra voice you are hearing is sung in the octave of the first voice. So, it is the same note just sung an eighth higher. The voice and notes of the Leo model all derive or stem from your center. This part of the Leo model illustrates, you - O a'u and family - aiga and the support needs to be the same in correspondence to each other for wellbeing of the physical, mental spiritual and emotional self.

Love ALOFA (love for yourself, love for what you do, love for others) and

Respect FA'AALOALO (respect for other thoughts, feelings, space and environment)

The next lot of voices illustrate love and respect weaving between the features of the Leo model.

The feature of Respect and Love bind the model together weaving in and around all the other parts. For me Love and Respect can look like many different things and so here, I wanted to use the many different colors of my voice and create 
a movement action to illustrate weaving "Aroha is truly a divine love because it knows no bounds, and is infinite." (Pere, 1997, p.6)

The Leo model will then leave you with the voice of Atua, or one's beliefs to end. This is to illustrate my belief in God as being the beginning and the end of all things.

\section{Creating the Leo model:}

Before creating the Leo model, I began to look at other indigenous models of understanding. I found most have common features and themes and most were based on health and the wellbeing of a person.

Looking at my family and how I was brought up, we are very simple people. We live by simple rules, lead simple lives so when creating my model, I wanted it to be very easy to understand.

Models like Te Wheke, Fonofale and Tivaevae all have something to say about the relationship of each feature working together,

"The dimensions are interwoven and this represents the close relationship of the tentacles" (Ministry of health, 2017).

"The concepts of Tivaevae are intertwined with each other rather than single separated..." (Te Ava, Airini and RubieDavies, 2014).

"...all aspects depicted in the Model have an interactive relationship with each other." (Fuimaono, 2001).

Collaboration, reciprocity and interrelating values and principles are articulated here and I wanted my model to make sure it was showing the same relationship between each with helping understand one works well with the other but together is much stronger, colourful.

The Leo model is very innovate using a QR code as a link to the sound scape. The model is also creative in a way which uses sound harmonies and melodies to illustrate the functionality of my model very different from a sketched, drawn model. 
I call myself a "Creative Native" and with it comes, out the box thinking, pushing of boundaries and coming up with new innovative ideas.

\section{References}

Fuimaono Karl Pulotu - Endemann. (2001). Fonofale model of health. Retrieved from: http://www.hauora.co.nz/resources/Fonofalemodelexplanation.p df

McNab, D. (2013). Indigenous Voices and Spirit Memory. Winnipeg, Manitoba: Aboriginal Issues Press.

Ministy of Health. (2017, May 18). Maori health models - Te Wheke. Retrieved from: https://www.health.govt.nz/ourwork/populations/maori-health/maori-health-models/maorihealth-models-te-wheke.

Te Ava, A., Airini., \& C Rubie-Davies. (2014). Akaraka akaouanga I te kite pakari o te tuki airani: Culturally responsive pedagogy. Pacific Asian Education, 2(2), 117-128. 